\title{
Deciding When To Initiate Social Security Benefits
}

Allen Atkins, Northern Arizona University, USA

Craig Bain, Northern Arizona University, USA

\begin{abstract}
People nearing retirement face a well-known decision: When should to begin taking social security benefits? The answer may not seem obvious since there are key trade-offs involved. The retiree can choose low benefits for a longer period of time, or high benefits for a shorter period of time, or something in between. The optimal initiation date that maximizes social security wealth is a quantitative question and it depends on the life expectancy of the person and on the real rate of return they expect to earn on their investments, among other things. We attempt to provide some answers to this practical and important question. Our focus throughout is on relatively highwealth individuals who will receive the maximum social security benefits. We show how the government's social security benefit calculator can be very misleading. We also include how the decision may be different for a married couple. We conclude with the following rough guideline. If you expect to make a good return on your investments, you should take the benefits early (i.e. at age 62). If you expect to make modest investment returns and you expect to live a long time, you should take the benefits later, (i.e. at age 70).
\end{abstract}

Keywords: retirement, social security, benefits, maximization

\section{INTRODUCTION}

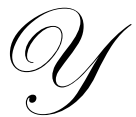

es, it's old news by now, we all know that the first of the Baby Boomers has retired. Kathleen CaseyKieschling was born one second after midnight on January 1, 1946. She became the first Boomer to apply for Social Security benefits. Kathleen was the first in a potential downpour of Boomers set to hit the Social Security system. However, with the economic downturn that started in 2008, and with uncertainty going forward, many Boomers are rightfully concerned about their retirements. In fact, many are considering deferring their retirement. For CPA's, who are often asked by clients to help them determine their maximum retirement benefits, this is an important issue to understand.

This article looks at one important aspect of the retirement decision. That is how to get the most out of your Social Security benefits. These days, given the uncertain economic conditions, many working people are looking to their Social Security benefits to play a bigger role in their retirement decision. Of course this has been written about, and there are many different scenarios presented to us. Although we cannot answer every question, we can look at areas that effect their retirement and provide valuable direction. A great number of the articles written to aid in the retirement decision are much too broad in their scope, make assumptions that don't lend themselves to specifically helping out clients, or they focus on an income range that is not relevant for our client base. The purpose of this article is to provide information that will allow readers to add significant value to the retirement of their clients. (For other articles that discuss other aspects of this decision see Atkins and Caliendo, 2009, Clements, 2002, Dalton, 2006, Fishbein, 2008, Fridrich, 2007, Garnett, 2006, Muskian, 2006, Undergrave, 2004, Vanzante and Firtzsch, 2008.

As our clients approach retirement, an important decision for them is when to take social security benefits. The earlier you begin taking your benefits, the less you receive. Full retirement age is 66 for those born between 1943 and 1954. For those born before 1943, full retirement age is younger and after 1954, full retirement age is older. For example, in 2008, a person in the highest earning category can receive $\$ 1682 /$ month at age 62 , 
$\$ 2288 /$ month at age 66 or $\$ 3077 /$ month at age 70 . If you retire early, at age 62 , you get about $26 \%$ less than the normal age of 66. If you wait until age 70 you get about $34 \%$ more than the normal age. These are significant differences in the return on your retirement investment. The two most important factors in the decision are how long you expect to live and what rate of return you can earn on your other retirement assets. Knowing either of these is impossible, but our job is to provide our clients with informed input for their decision.

Many articles have been written on this topic and there is no consensus on what retirees should do. Some recommend waiting before beginning to collect benefits. Others recommend taking the money early. Finally, many articles find that it depends on several factors and they attempt to help prospective retirees make the decision based upon their personal situation. This paper falls in to the third group.

Several factors impact the decision on when to initial benefits. These include whether or not a person has additional retirement income sources, whether or not they are going to continue to work and what their marital status is.

Many articles focus on individuals. This paper includes married couples.

If a person has no savings and needs a social security payment to live on then clearly they should begin their benefits as soon as they can. Our analysis focuses on a person who can afford to wait to begin collecting benefits without any undue hardship should they choose to do so. For these individuals the appropriate decision is to begin collecting social security to maximize the present value of all their expected benefits. Lastly, if a person chooses to begin collecting benefits at age 62 but continues to work, social security benefits are taxed (currently) at the high rate of 50\%. Thus, it makes little sense to take benefits early unless the client intends to stop working.

\section{THE PRESENT VALUE OF BENEFITS UNDER DIFFERENT SCENARIOS}

The two most important factors affecting the present value of social security benefits are the length of time receiving the benefits before death and the rate of return they earn on invested funds.

We start with a baseline life expectancy of 84 years of age. This is because actuarial tables published by the IRS indicate a 62 year old male currently has a life expectancy of 83.5 (for ease, we will use 84) (see http://www.irs.gov/pub/irs-pdf/p590.pdf page 94). We use real rates of return in our calculations. These are rates of return an investor realizes after subtracting the rate of inflation. We use these rates because social security benefits are adjusted for inflation each year. Participants are therefore compensated for changes in inflation so the relevant investment return for analysis becomes returns above the inflation rate. The analysis is then still relevant during periods of high inflation. This is important because some are predicting inflation may become high in the near future.

The retirement ages we consider are early (62), regular (66) and late (70). The maximum monthly benefit amounts for the three retirement ages are $\$ 1,682 ; \$ 2,288$; and $\$ 3,077$ respectively. These ages cover the main retirement ages considered by the majority of decision makers. The analysis performed considers the present value of the benefits collected under these different scenarios.

The government's social security page, provides benefit estimates from their benefit calculator (see http://ssa.gov/ click on the RETIREMENT tab then "Calculate your benefits"). This page also gives a "break-even age" between choices. For example, using the information in this paper they calculate that if you begin your benefits at age 62 instead of age 70 your "break-even age" will be 79.5 years. This means that if you live beyond age 79.5 you would be better off waiting until age 70 to start taking benefits. If you do not live to age 79.5 you are better off initiating your benefits at age 62. Remember, in general, currently, a 62 year old man has a life expectancy of about 84 years.

This is where most analyses stop. However, this is really where we need to begin the analysis. The above breakeven calculation is only correct if you assume a real rate of investment of $0.0 \%$. That means that your other investments are only earning an amount equal to inflation and no more. This rate of return is analogous to investing 
in Treasury Bills, currently a safe investment, but offering no real rate of return above inflation. Is this a reasonable assumption even in today's topsy turvy investment world? For many individuals with reasonable wealth, this assumption is most likely not at all reasonable. When these individuals spend their social security check it allows them to keep part of their savings and other retirement money invested, earning a return on those funds. The rate of return earned on those funds affects the "break-even age" dramatically. If a person earns a real rate of return anywhere above zero then the social security "break-even age" is misleading and inaccurate.

\section{MODELING BENEFITS BREAKEVEN}

The following analysis considers the present value of social security benefits under different life expectancies and different rates of return. Break even ages are calculated for the different assumptions.

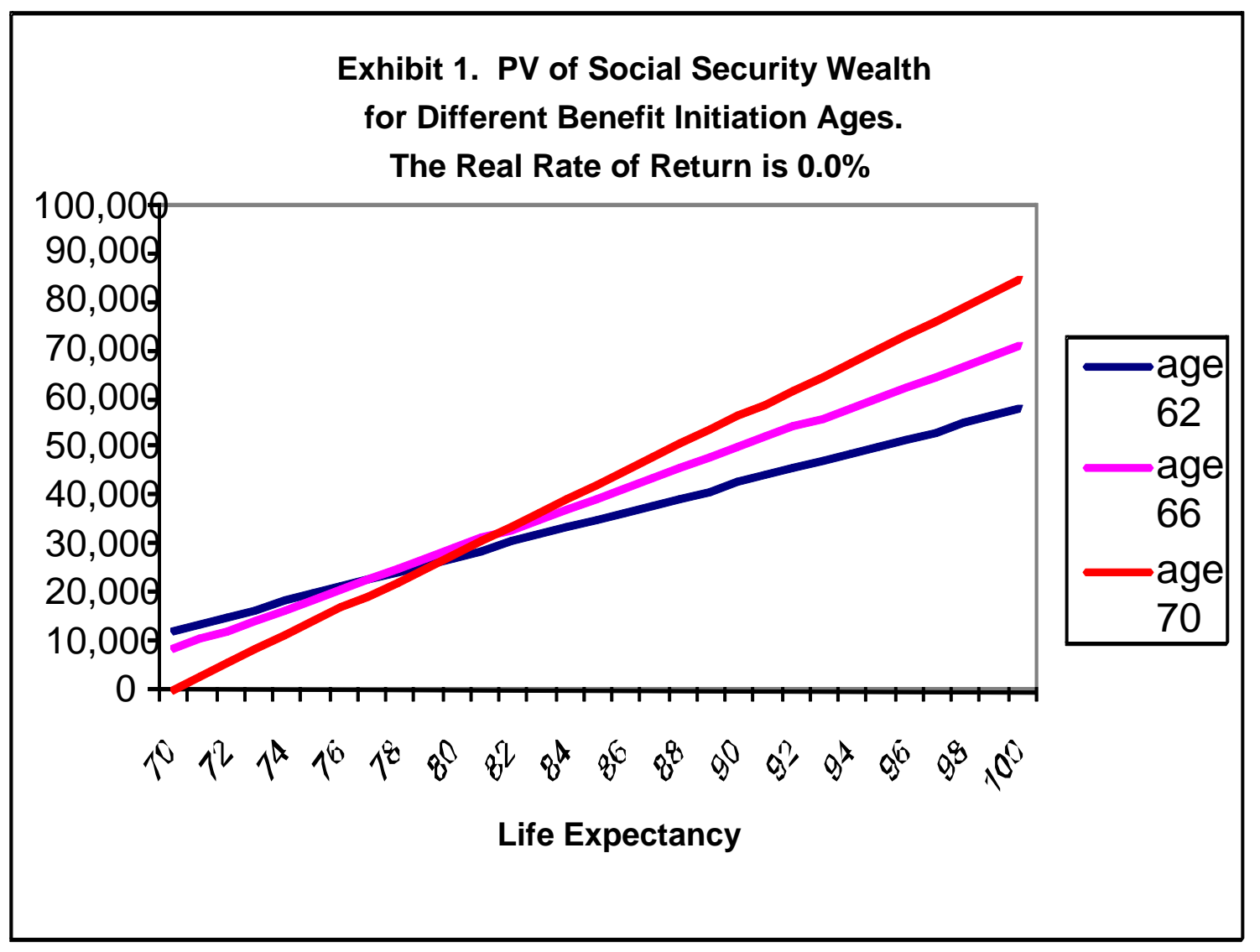

Exhibit 1 shows the assumption used on the Social Security website. This is the present value of total benefits at various ages of death if the real rate of return is zero percent. The three lines show each age of retirement. The highest line on the graph represents the largest present value and thus the optimum age to initiate benefits given a certain life expectancy. The figure shows that the "break-even age" between initiating at 62 vs. 66 is about 76.8 years. This is the point where the 62 line crosses the 66 line indicating an identical present value. The "break-even age" between initiating at 62 vs. 70 is 79.5. The "break-even age" between initiating at age 66 and 70 is about 81.6. So, if a person's life expectancy is less than 76.8 years of age it is beneficial to begin collecting social security benefits at age 62. The incremental payments from retiring later are not worthwhile if a person does not live very long. If a person expects to live to age 81.6 or older it is best to wait until age 70 to retire. With a life expectancy between the ages of 76.8 and 81.6 retiring at age 66 is optimum. This suggests that if a person is in poor health they should probably begin collecting benefits as soon as possible, at age 62. If a person is in good health and 
thinks they will live beyond age 81.6, they should wait until 70 to begin benefits. Keep in mind that this exhibit assumes a real rate of return of zero and this exhibit matches the calculations on the government's social security page. This is clearly a pessimistic view of investment returns. However, it might be fairly accurate for a client who is very conservative and holds most of their money in money market accounts and therefore earns very little above the rate of inflation.

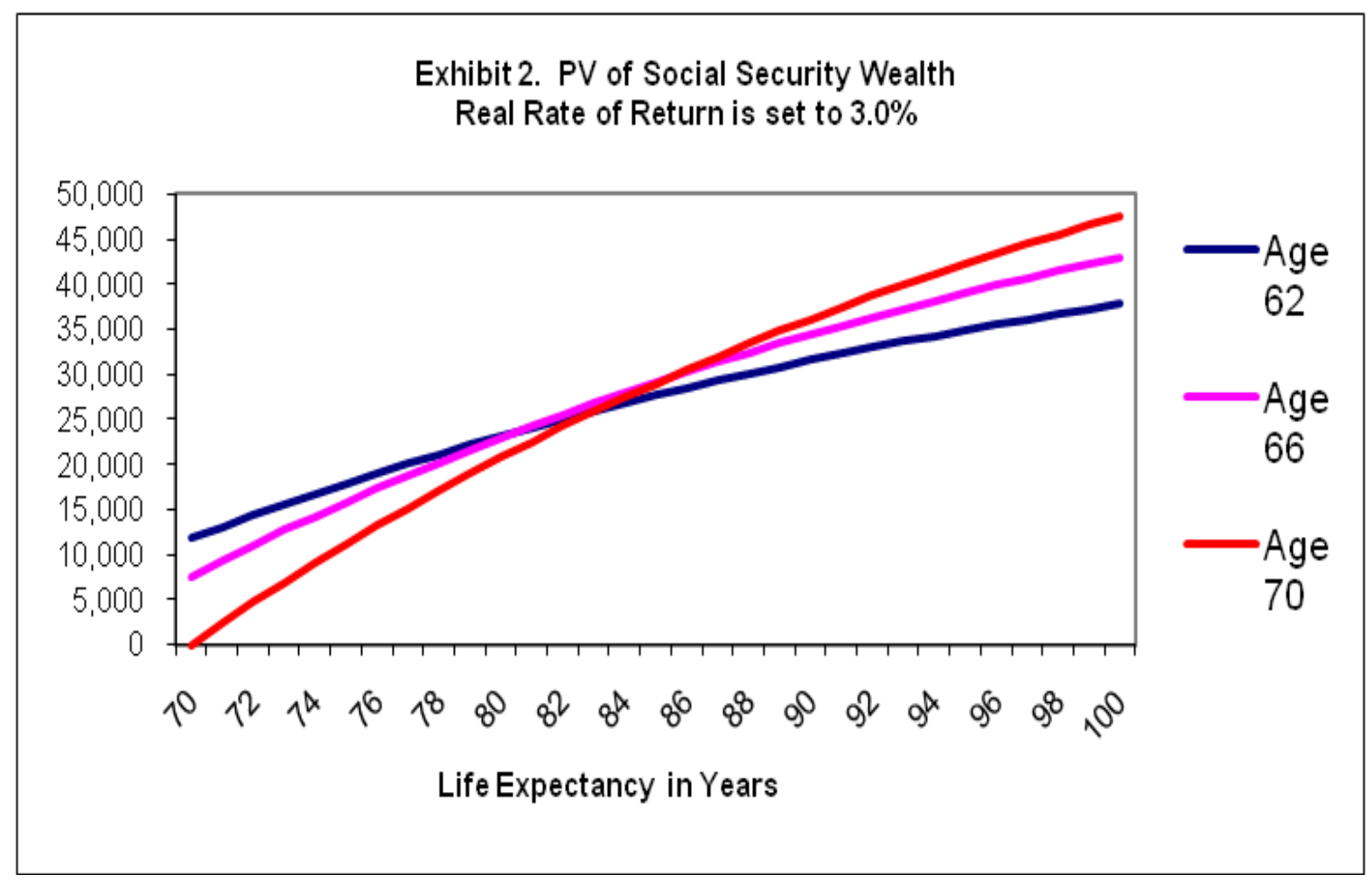

Exhibit 2 shows the present value of total benefits at various ages of death assuming a real investment rate of $3.0 \%$. Note that a real rate of return (adjusted for inflation) on private funds has averaged $3.5 \%$ over the past 50 years. With the market uncertainty we face now and going forward, we see many investors reconfiguring their portfolios to reduce risk. As a result a somewhat lower rate of return seems appropriate. This may be especially true for people as they near retirement age. So we have chosen a rate of $3.0 \%$ for this chart. Note that the lines cross at a much older age indicating a "break-even age" older than exhibit 1. The "break-even age" between beginning retirement at 62 vs. 66 is about 80.5 years. This is the point where the 62 line crosses the 66 line indicating an identical present value. The "break-even age" between initiating at 62 vs. 70 is about 83.1. The "break-even age" between initiating at age 66 and 70 is about 85.3. The break even ages are on average about 3.7 years older than in exhibit 1. This is because as you earn a higher return on your social security payments it becomes more advantageous to get your benefit payments sooner. For this case, anyone who does not expect to live until age 80.5 should begin collecting their benefits at age 62. If a person thinks they will live to between ages 80.5 and 85.3 , they should begin collecting benefits at age 66. You need a life expectancy of 85.3 or older to delay benefits until the age of 70 . 


\section{Exhibit 3. PV of Social Security Wealth for Different Benefit Initiation Ages: The Real Rate of Return is $7.2 \%$}

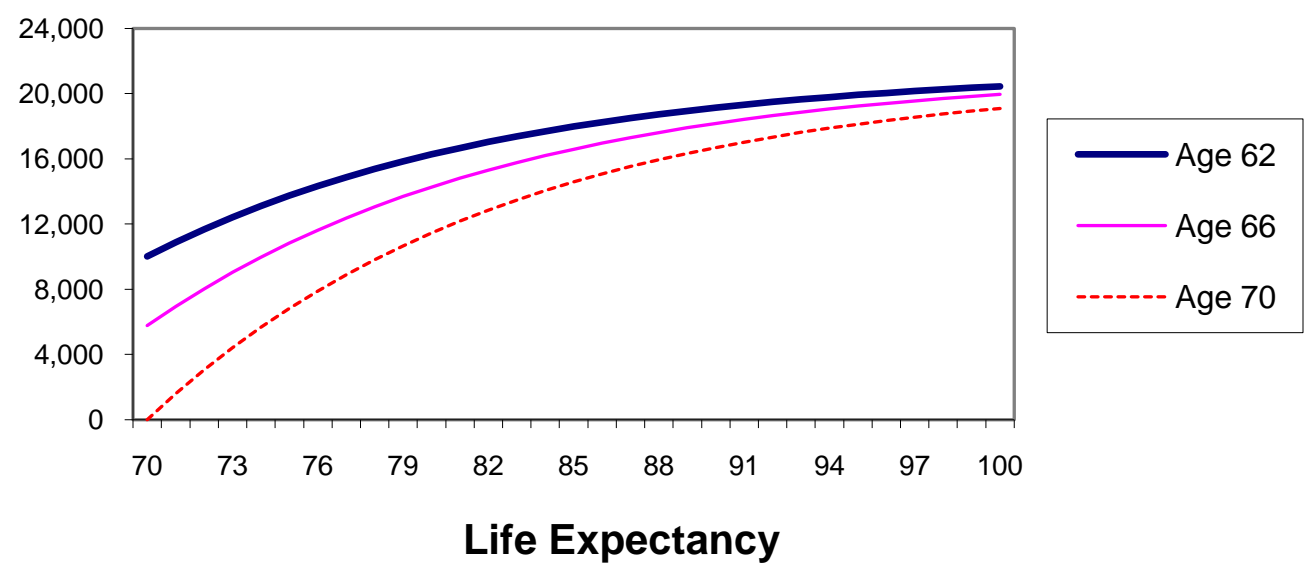

Exhibit 3 shows the present value of the benefits if the real rate of return is $7.2 \%$. This real rate of return (a return above the rate of inflation) may be an optimistic view of investment returns. However, we include it for a few reasons. First, this is a convenient rate because many people are familiar with the rule of 72 . To use this rule of thumb the rate of assumed growth is divided into 72 to find how long it takes, in years, for the initial investment amount to double. If we use an investment rate of $7.2 \%$, then our initial investment amount will double in about ten years. Second, it could be realistic for an aggressive investor, who holds a large portion of their wealth in stocks, to realize a return of $7.2 \%$. This is assuming the stock market does reasonably well and some forecasters do predict a $10 \%$ return in the years following the current recession. In this figure the three age lines never cross. The maximum present value is always obtained by initiating benefits at age 62. This means that it is never in the best interest of the investor to wait to collect benefits if they expect a high rate of return. This conclusion would hold and be even more dramatic at any rates higher than $7.2 \%$. Getting the benefit checks early is very valuable when a high rate of return can be earned.

Exhibit 4: Break-Even Ages for Various Real Rates of Return

\begin{tabular}{|c|c|c|c|}
\hline Ages considered & Real return $=\mathbf{0 . 0 \%}$ & Real Return $=\mathbf{3 . 0 \%}$ & Real return $=\mathbf{7 . 2 0 \%}$ \\
\hline 62 vs. 66 & 76.8 & 80.5 & $100+$ \\
\hline 62 vs. 70 & 79.5 & 83.1 & $100+$ \\
\hline 66 vs. 70 & 81.6 & 85.3 & $100+$ \\
\hline
\end{tabular}

Exhibit 4 shows a summary table of the break even ages for the previous three exhibits. The table shows how different rates of return can change a retiree's "break even age". This table points out that for some investors, the government's benefit calculator can be misleading. The government's "break-even" calculation are shown in column one which is the case where the real return equals zero. Clearly a retiree who invests reasonably well will face a much older "break-even age". In fact, an investor who earns a $7.2 \%$ real return will never "break-even" if they delay initiating their benefits.

Another way to analyze how the rate of return affects social security benefits is to hold the age of death constant but vary rates of return. Exhibit 5 shows the present value of wealth under different levels of return for the 
person who dies at age 84. This is the expected actuarial age of death for a 62 year old male today. Exhibit 5 shows that if a person lives to age 84 and can earn about $5 \%$ or more, they are better off beginning collecting benefits at age 62. If the real rate of return is below about $2.0 \%$ then the person is better off waiting until age 70 to begin benefits. For any real rate of return between 2\% and 5\% then it is best to initiate benefits around age 66 .

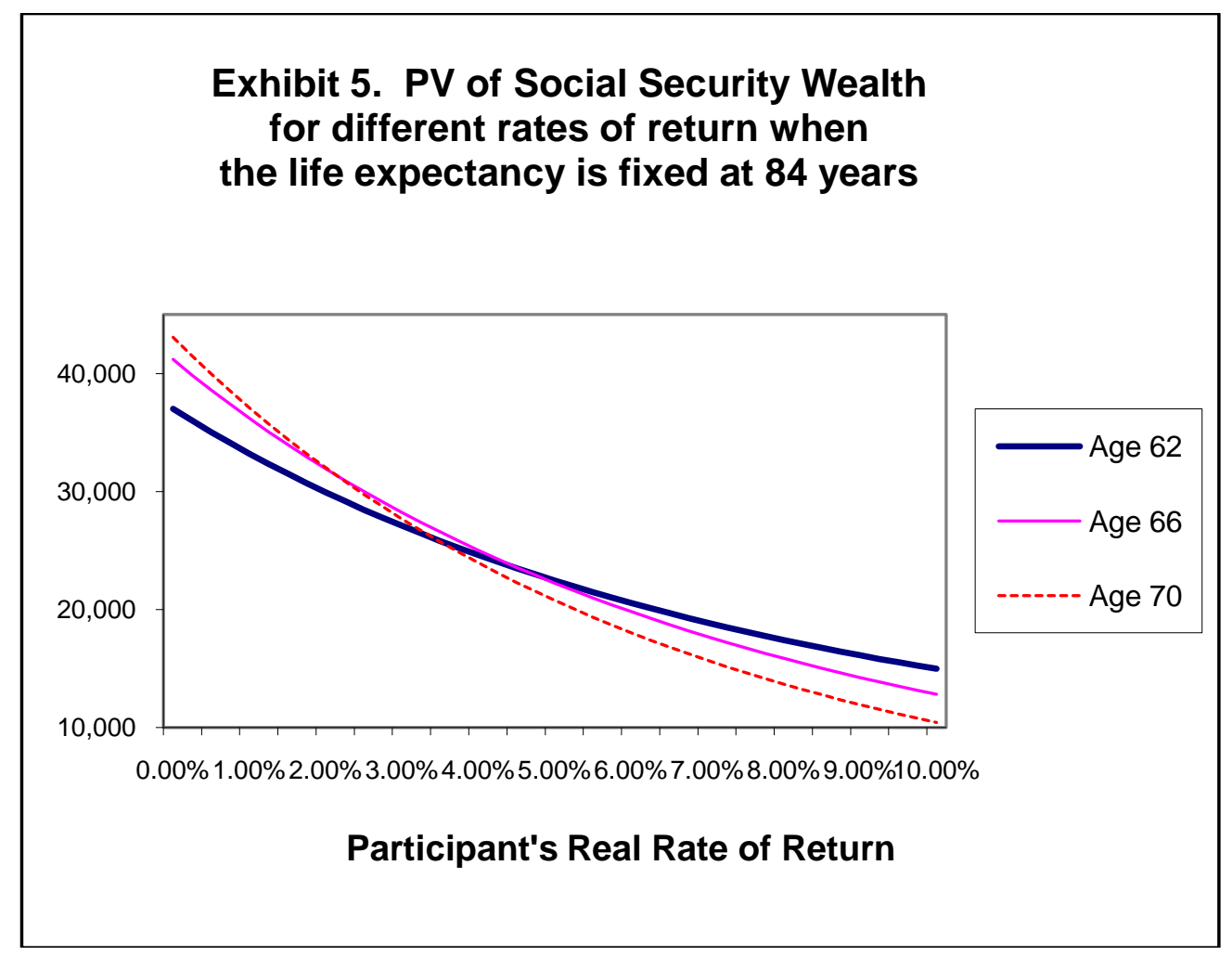

From these five exhibits we can conclude several things. The longer you expect to live the more beneficial it is to wait and collect social security later. Also, for average rates of return (a real return of about 3.0\%), anyone expecting to live to at least 85.3 would be better off to wait until age 70 to begin collecting benefits. In addition, the lower the return that is expected on an individual's other funds the better off they are to wait and collect social security later. However, for those who expect to earn a high rate of return, it is virtually always better to begin collecting benefits at age 62 .

\section{THE PRESENT VALUE OF TOTAL BENEFITS FOR A MARRIED COUPLE}

The previous analysis was done for a single person. The actuarial tables predict that the average 62 year old male will live to age 84 . If the person is married, however, some of the benefits continue as long as one of them is alive. In general, if one spouse dies and if the surviving spouse is about the same age as the deceased, the surviving spouse can chose to receive their own benefits or half of their deceased spouse's benefits, whichever is greater. This of course has a profound impact on the decision.

Actuarial tables show that, for a couple who are approximately the same age (say 62), there is a $50 \%$ chance that one of the two will live to the age of 91 (IRS 2003 mortality tables). There is a $25 \%$ chance that one of the two will live to the age of 96 and a 10\% chance that one will live to age 100. Exhibits 1-3 show how this may affect the present value of the total benefits. At ages of 85.3 or older, with a real rate of return of $3.0 \%$, it becomes most advantageous to wait until 70 to collect benefits. When a couple considers joint life expectancy, this greatly increases the number of years that benefits may be collected and makes it more worthwhile to retire later even if the 
surviving spouse only receives one half of the benefits. This shows that when considering both spouses in a couple, it may be more advantageous to wait since some benefits will likely accrue to one of the two for many more years. If the couple expects to earn a high return, however, it is still beneficial to begin collecting benefits at age 62 . Exhibit 3, with a real rate of return of $7.2 \%$, shows that even if the life expectancy is 100 years of age, the present value of the benefits is greater by collecting benefits starting at age 62 .

\section{CONCLUSION}

An important decision retirees in the United States face is when to begin collecting social security benefits. The two most important considerations in this decision are the life expectancy of the person, or couple, and the expected rate of return on their investments. The longer a person or couple expects to live the more advantageous it is to wait and begin collecting larger benefit checks at a later time. Also, the lower the expected rate of return on investments, the more beneficial it is to wait and begin collecting benefits later. So a person who expects to live a long time and is a conservative investor may wish to wait to initiate Social Security benefits.

A somewhat surprising result is that for someone who expects to earn a high real return on their investments (say $7.2 \%$ or more), it is virtually always better to begin collecting benefits early. In this case, even a person who lives well beyond the average age will be better off collecting their benefits early. Even though the benefit checks collected at an earlier age are smaller, the higher return earned on those benefits more than compensates for it.

\section{ACKNOWLEDGEMENT}

We would like to thank Frank Caliendo for his help on the tables and charts.

\section{AUTHOR INFORMATION}

Allen B. Atkins is a Professor of finance at Northern Arizona University. He received a BA in Economics from Dartmouth College and Ph.D. in Finance from the University of Texas. He has won numerous teaching awards and has published widely in the area of finance including articles in the Journal of Finance, the Journal of Financial and Quantitative Analysis, the Journal of Financial Research and Organizational Behavior and Human Decision Processes.

Craig Bain PhD, CPA (inactive) is Accounting Area Coordinator and Professor of Accounting at Northern Arizona University. He has published numerous articles and in 2003 was awarded the Excellence in Teaching Award from the Arizona CPA Foundation for Education and Innovation.

\section{REFERENCES}

1. Atkins, Allen B. and Frank Caliendo, 2009, Strategies for Maximizing Social Security Benefits, The Journal of Wealth Management, Summer, Vol. 12, No. 1. 1-7.

2. Clements, Jonathan, Want a Comfortable Retirement? Taking Social Security Early Could Be a Mistake, Wall Street Journal, 2002, May 8, Vol. 239, p D1.

3. Dalton, Thomas M., Retirement at 62: Is Receiving Social Security early Worth It?, CPA Journal, 2006, June, Vol. 78, no. 6, p 42.48.

4. $\quad$ Fishbein, Robert, "Honey, I Shrunk Our Retirement Benefits,", Best's Review, 2008, June, p88.

5. Fridrich, Tom, "Early Retirement: Building a Bridge to Social Security", National Underwriter, 2007, Nov. 5, p30-32.

6. Garnett, Kathryn, “Social Security: What's The Magic Age,” Journal of Accountancy, 2006, July, p28-32.

7. Muskian, Robert, calculating Break-Even Ages for Delaying Social Security Beyond Normal Retirement Age, Journal of Financial Planning, 2006, March, Vol. 19, issue 3, pp. 70-80.

8. Undergrave, Walter, When To Take Social Security, Money, 2004, December, Vol. 33, Issue, 12 pp69-70.

9. VanZante, Neal R., and Ralph B. Fritzsch, "Social Security Planning: Emphasis on married Couples," The CPA Journal, 2008, September, p 48-51. 


\section{NOTES}

